\title{
Bechäftigtendatenschutz - Neustart nach europäischer Art
}
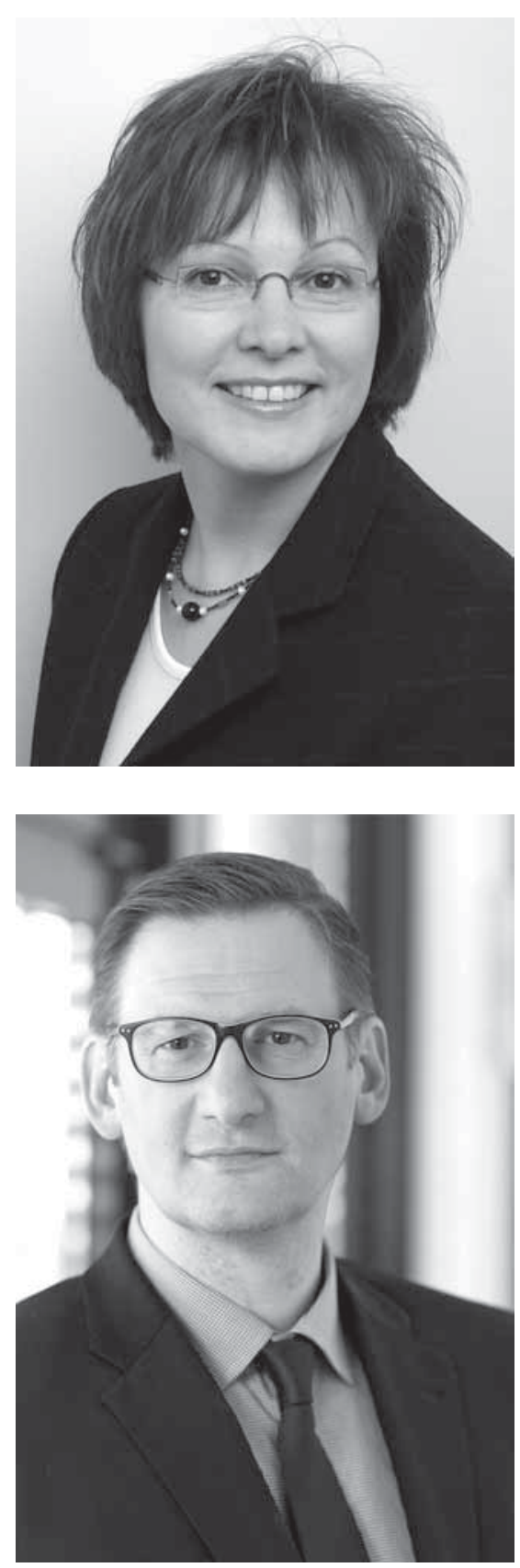

Nach langem europapolitischem Ringen ist mit dem Inkrafttreten der DatenschutzGrundverordnung (DS-GVO) im Mai 2016 besiegelt worden, dass der Datenschutz insgesamt vor einer einheitlichen europäischen Neujustierung steht. Spätestens mit der verbindlichen Geltung der Verordnung im Mai 2018 ist in den Mitgliedstaaten der Europäischen Union ein einheitliches Datenschutzrecht gegeben. Aber: Im Kontext der Beschäftigtendaten können spezifischere Vorschriften erlassen werden. Diese Öffnungsklausel bietet dem Gesetzgeber hierzulande die Chance, den Beschäftigtendatenschutz nun endlich anzupacken und damit im Hinblick auf die zunehmende Digitalisierung der Arbeitswelt wegweisend zu gestalten.

Naturgemäß sind die Diskussionen aktuell in der Fachöffentlichkeit noch im Fluss, nicht aber etwa randständig. Zahlreiche Beiträge und Neuveröffentlichungen zeigen dies. Das vorliegende Schwerpunktheft will zu diesen Diskussionen beitragen und betrachtet hierzu ausschnittsweise das Thema des Beschäftigtendatenschutzes, der durch Art. 88 DS-GVO zum Gegenstand von nationalen Überlegungen gemacht wird und in diesem Heft aus aufsichtsrechtlicher, richterlicher und rechtspolitischer Sicht näher betrachtet wird.

Hierzu wird durch Stelljes, stellvertretender Leiter einer Landesdatenschutzbehörde, beleuchtet, inwieweit der Beschäftigtendatenschutz durch die DS-GVO tatsächlich gestärkt wird und dadurch die Überwachungsrisiken, denen Beschäftigte in Zeiten der Digitalisierung ausgesetzt sind, verkleinert werden. Im Ergebnis plädiert er für die Regelung durch ein Beschäftigtendatenschutzgesetz. Spelge, Richterin am Bundesarbeitsgericht, sieht in ihrem Beitrag erhebliche Auswirkungen auf den Beschäftigtendatenschutz und hält § 32 BDSG für unzureichend, der Verordnung zu genügen. Daher soll ihrer Ansicht nach der Gesetzgeber die verbleibende Zeit bis Mai 2018 konstruktiv nutzen, denn ein Nachjustieren ab dem Zeitpunkt der direkten Anwendung der DS-GVO sieht sie mit Verweis auf Art. 88 Abs. 3 DS-GVO kritisch. Schließlich wird in einem weiteren Beitrag das Konzept der Verordnung, wonach spezifischere Vorschriften zum Datenschutz für Beschäftigte durch die Mitgliedstaaten etabliert werden können - und zwar durch Gesetz oder Kollektivvereinbarung- genauer untersucht. Wir wollen darlegen, dass damit der Beschäftigtendatenschutz, je nach neuem Datenschutzrecht in Deutschland, noch stärker in die Hände der Sozialpartner als bisher gelangen wird. Hier werden Chancen, aber auch ein Mehr an Verantwortung für die Sozialpartner gesehen. Denn durch Art. 88 Abs. 2 DS-GVO, der auf die menschliche Würde verweist und gleichsam die weite Dimension des Datenschutzes aufzeigt, wurde die Messlatte für tarifliche oder betriebliche Regelungen hoch angelegt. Bereits bestehende wie auch neue Kollektivvereinbarungen müssen diesem Maßstab angepasst bzw. entsprechend gestaltet werden. Ein schon seit August 2016 öffentlich bekannt gewordener Referentenentwurf des Bundesministeriums des Inneren (BMI) weist zur wirksamen Umsetzung der DS-GVO in die falsche Richtung. Damit wird der Versuch unternommen, einzig durch den Erhalt des $\S 32$ BDSG - und ohne die durch Art. 88 DS-GVO vorgegebene Regelungsnotwendigkeit - spezifischere Regelungen zum Beschäftigtendatenschutz durch Gesetz oder Kollektivvereinbarungen in einem neuen $\S 33$ ABDSG umzusetzen. Dieser Vorschlag des $\mathrm{BMI}$ ist, und hierüber herrscht in der dazu bereits geführten Fachdiskussion Einigkeit, als unzureichend anzusehen.

Es bleibt also spannend im Datenschutzrecht für Beschäftigte. Der kurze Zeitraum für die Umsetzung der Öffnungsklausel in Art. 88 DS-GVO sollte besser genutzt werden, um die notwendigen und vom europäischen Gesetzgeber gewollten Schutzmechanismen im Beschäftigungskontext zu schaffen. Nicht, dass es am Ende heißt: Chance verpasst.

Kerstin Jerchel und Jens M. Schubert 